\title{
ON THE PREDATORY HABITS OF LIONS AND HYAENAS
}

\author{
by \\ F. C. ELOFF, \\ University of Pretoria.
}

So much has been written about the predatory habits of the African Lion (Panthera leo) and the spotted hyaena (Crocuta crocuta) that it seems unlikely to unearth anything new about these wellknown animals. Yet the writer made certain observations in the Kalahari Gemsbok Park which prove that the last word on these animals' predatory habits has not yet been spoken.

\section{The Lion (Panthera leo)}

Travelling along the bed of the Auob River one night, we saw two lionesses stalking a gemsbok which was grazing against the slope of a dune. With a powerful light focussed on him the gemsbok kept on grazing peacefully, while the lionesses were also completely unperturbed by the light and indeed appeared to take advantage of the situation.

Making use of every possible cover - mainly insignificant shrubs and grass tufts - they moved closer and closer. Keeping iheir bodies low they seemed at times to become almost invisible, even in passing over terrain which seems to offer no cover at all.

They stalked to the edge of the circle of light, hesitated a few significant moments and then one lioness darted forwards. With an enormous leap she landed right upon the unsuspecting victim's haunches. Whether she miscalculated her jump, or whether the gemsbok was too fast for her, is impossible to say. Nevertheless, the terrified gemsbok threw the lioness to the ground and siaggered her with a terrific kick against the chest. The frightened gemsbok raced down the dune. The other lioness made a desparaie attempt to cut him off, but it was too late, and the gemsbok seemed to vanish in a cloud of dust.

This incident stimulated my interest and in discussing it with the Nature Conservator the following day I was promptly told that the Kalahari lion never atiacks its prey from in front, as the African lion is traditionally supposed to do. Instead, it always jumps on its victim's haunches, breaking its back, after which the lion finishes him off, seizing it by the throat or crushing its neck. 
I decided to carry my investigations further and was fortunate in coming across two fresh lion kills. In both cases the victim was a gemsbok. Carrying out a dissection it was revealed that, in both cases, the back was broken between the last lumbar and ihe first sacral vertebra and that the spinal cord was snapped at this point.

A third kill was found on the floor of a large pan. It was a few days old and stripped bare by vultures. Examination revealed that the back was broken in an identical way. The skeleton was not pulled apart as hyaenas generally do and it appeared, therefore, to be a lion kill, but it could not be ascertained beyond doubt.

In all three cases it was observed that the break in the back was upwards and not downwards as one would perhaps expect it to be if it was caused by the impact of the lion's heavy body landing on the gemsbok's back.

It was explained by the Nature Conservator that the lion, on landing on its victims' back, digs its teeth deep into the haunches and with a jerking motion upwards breaks its viciims' back at what appear to be a weak link in its vertebral column.

This dislocation, or break, in the gemsbok's vertebral column at this particular spot is of special interest. It is not the purpose of this paper to discuss ihe architectural construction of the gemsbok's vertebral column. Yet it is of interest to point out that in a paper on the construction of the vertebral column, Slijper (1946) maintained that in the ungulates the mobility of the back is practically limited to the lumbo-sacral joint and this area would iherefore also be the weakest link in the vertebral column.

This appears to be a contradiction of an earlier statement (p. 38) that the mobility of the mammalian vertebral column is maximal in its diaphragmatic region (post-thoracic vertebrae), and that the vertebral column has its weakest link in this region.

However, his statement that the mobility in the vertebral column of ungulates is practically limited to the lumbo-sacral joint, appears to be borne out by the author's findings in the gemsbok.

The greater mobility of the vertebral column in the lumbo-sacral joint might be attributed to the inseriion of the epaxial muscles in the lumbosacral region, mainly the latissimus dorsi, whose insertion tends to shift from the neural spines of the lumbar to those of the sacral vertebrae and ihe addition of a special element, viz. the gluteal tongue which, according to Slijper, is a special characteristic of the ungulates.

The mobility of the lumbo-sacral joint is further enhanced by the presence of a large opening between the laminae of the last lumbar and the first sacral vertebra leaving the neural canal wide open dorsally. This space appears io be a fairly general characteristic of mammals and it probably increases the mobility of the lumbo-sacral joint. Stability 
seems therefore to be sacrificed for mobility.

From the above evidence it appears fairly obvious that the lumbosacral joint is indeed the weak link in the gemsbok's vertebral column.

It also becomes clear why the vertebral column breaks upwards instead of downwards. With the animal's centre of gravity lying between the front- and hindfeet, and the vertebral column stretched to the full in a dorsal direction, like the bow of a bow and arrow, any weight on the hindquarters will cause it to sag down, pulling away from the centre of gravity and subjecting the vertebral column to terrific strain. This will especially happen if the animal is in the running position, with the hind legs swinging forwards below the body, extending the curvature of the rump to the utmost. This partly explains why, in the incident witnessed by the author, the gemsbok's back was not broken when attacked in a standing position.

In spite of these apparent weaknesses in the vertebral column the dislocation of the zygapophysial points at the lumbo-sacral junction demands terrific force. It is pointed out by Sliiper that in ungulates "the praezygapophyses embrace the posizygapophyses in such a manner that the joints are practically immovable". Yet this is exactly where the dislocation takes place in the gemsbok. The postzygapophyses seems to be partly wrenched out of its sockets and this is facilitated by the lion's alleged habit of biting into the gemsbok's rump and jerking it upwards with violent force.

The above observations and speculations can be summarised by saying that the gemsbok, as perhaps every other ungulate, has a weak link in the vertebral column and the Kalahari lion exploits this weak spot - the Achilles-heel in its prey's anatomy - in a masterly way. Whether it uses the same technique in killing ihe eland, red hartebeest and blue wildebeest, the other large antelopes in the Gemsbok Park, I am unable to say. Mr. J. D. le Riche, the Nature Conservator, however, witnessed many lion kills in his long association with this park and can vouch for it that the Kalahari lion kills horses, donkeys, cattle, blue wildebeest and eland in exactly the same way as described above. No other killing technique was observed.

How did the Kalahari lion come to adopt this method of killing its prey? The lion's usual method of killing its prey, which it seems to know by instinct according io observations by Joy Adamson (1960), is so well known and corroborated by so much evidence, that it hardly needs description.

Guggisberg (1961) who brought together all the available data on the lion's habits in his delightful book Simba, writes as follows on the lion's methods of killing iis prey: "Small animals are knocked over with a quick blow of the paw, and finished off with a bite in the neck or throat. Animals the size of a wildebeest or a zebra are thrown down by the impact of the lion hurling himself against the front part of the body. 
With one paw the attacker often catches hold of the forehead or the nose of the victim, pulling the head down to the chest so that in falling forward the animal breaks its neck." He points out, however, that the breaking of the neck does not always take place and indeed, it might be the exception and not the rule.

However, according to all available evidence the lion seems to focus his attack to the front part of the body. Naturally, ihere will always be exceptions, e.g. where more than one lion attacks a large animal like a buffalo, some may attack from behind. While one or more lions attack it from in front to engage its attention, another will grab its hind legs from behind, apparently with the idea of incapacitating the animal by biting through the tendons of its hind legs. Such a case is cited by Stevenson-Hamilton (1954), and a similar case was brought to the author's notice by personal communication. The same system is said to be adopted when a party of lions attack a giraffe.

To kill a gemsbok in the traditional way is a method fraught with danger and Mr. le Riche can recall at least one case of a lion killed by a gemsbok. He came upon the scene soon after the event and was able to reconstruct the whole drama. A gemsbok was cornered by a lion and lioness. In the struggle that followed the lion was stabbed in the chest, one horn running through its body, emerging behind the shoulder. The lion was probably killed instantaneously but the brave gemsbok now became an easy target for the lioness and was killed on the spot.

Fitzsimons (1925), relates an instance of a hunter discovering the remains of the skeleton of a lion and a male gemsbok in Norihern Rhodesia. The latter's horns penetrated the lion's body through the ribs, while the gemsbok's neck was crushed, indicating that both had died after a violent struggle.

Roosevelt (1915), came across several hundred kills in his wanderings ihrough Africa and makes a few remarks on the way some of the animals, including the oryx, were killed. From these observations it is evident that Roosevelt did not find anything unusual in the lion's method of killing the oryx. What he does say about the oryx is that it is reputed to defend itself against the lion, but he was unable to confirm this. It seems reasonable to conclude, therefore, that the East African lion kills the oryx in the usual way.

That lions differ in habits is of course not strange. Guggisberg comments on the difference in jumping powers of the lions inhabiting the southern and north-eastern paris of Africa, and of the difference in eating habits. A difference in killing methods between lions from different parts of Africa, therefore, seems to be quite natural.

Although the wardens of the Kalahari Gemsbok Park are quite emphatic that, in their own experience, the Kalahari lion never kills its prey in any other way than related above, and although the writer's 
own observations corroborate this, one must not be too dogmatic about this. Yet it seems fairly certain that the Kalahari lion adopted a new hunting technique, a technique that appears to be the only efficient method of counteracting the lethal horns of its most common prey in this semi-desert country. By perfecting this killing method the lion very efficiently eliminates the gemsbok's most dangerous weapon.

\section{The Spotted Hyaena (Crocuta crocuta)}

The hyaena is often described as a vile and repulsive animal. To this writer the hyaena is far from being vile and repulsive; instead, I regard it as one of our most interesting animals and its weird lond-drawn-out call is to me the symbol of unspoilt Africa, a last link with this continent's vanishing fauna.

Whether the hyaena could be regarded as one of nature's successes is of course a debatable question. Yet, due io its varied habits and its downright cowardice when the occasion demands a timely retreat, the hyaena has been able to hold its own against strong competition.

Phylogenetically a miocene offspring of the civets, ihe living hyaena's ancestors must have been predators in the true sense of the word. Today the hyaena is generally regarded as a scavenger, although it is known to hunt and kill its own prey. The extent to which ihis happens seems to differ considerably in various parts of Africa and it is on this point that the writer wishes to elaborate.

To appreciate the aberrani habits of the spotted hyaenas in the Kalahari Gemsbok Park it is desirable to look into its habits in other parts of Africa.

The best available study on the habits of the spotted hyaena is that by Harrison Matthews (1939). From this study the hyaena emerges in the first place as a scavenger, although it does its own killing occasionally and is quite capable of pulling down game up to the size of the zebra.

In connection with the hyaena's predatory tendencies Johnston 11886, quoted by Matthews) wroie more than seventy years ago that "the spotted hyaena is a much more predatory animal than one generally imagines. Not only does it steal sheep and calves from the herds, but it even carries off children and will often attack wounded or weakly men."

Concerning the hyaena's social behaviour Matihews maintains "that there is some degree of gregariousness, but it appears to be little developed beyond random proximity". He adds that the hyaena does not appear to hunt in large packs, two to three being ihe number usually found together in running down game.

From the works of Kearton (1929), Pitman (1942), Roosevelt (1915), Kirby (1899), Selous (1908), Stevenson-Hamilton (1954) and other wellknown authors on African wild life, the hyaena is clearly a scavenger, subsisting mainly on carrion and bones. It is also described by some of the abovementioned authors as gregarious, troops consisting of up to 
twenty individuals not being uncommon. Although not a game killer like the hunting dog, instences are cited where packs of hyaenas have cornered and killed fullgrown antelopes. This, however, appears to be the exception and Kearton's statement that the hyaena will rarely attack anything that has power to defend itself seems to be an appropriate description of this animal's habits in every part of Africa where a study of its habiis was made.

More recently there is a fine study of the spotted hyaena by Deane (1962), who maintains that although the hyaena does not possess the speed and huning abilities of other predators it is nevertheless capable of "bringing down quite large game, although most of their victims are immature or injured animals". An instance is reported where a lone hyaena chased and killed a three-quarter grown wildebeest.

Judging from these reports the spotted hyaena appears to be a curious mixture of hunter and scavenger, living on carrion when it is available and resorting to hunting and killing its own prey when its natural food is unobtainable.

In contrast to this the spotted hyaena of the Kalahari Gemsbok Park is a true hunter, marauding in packs like ihe African hunting dog. And it is not due to a change of habit forced on him through the disappearance of game and the larger predators on whom he depends for a regular supply of food. Within living memory the greatest part of the northwestern Cape and ihe Kalahari teemed with thousands of springbok and other game animals.

Mr. le Riche, present Warden of the Kalahari Gemsbok Park, since its establishment in 1931, is quite emphatic that the hyaena has not undergone any change in its habits during his more than thirty years of experience.

In the present author's own experience he is not able to recall a single instance of a hyaena feeding on the remains of animals killed by other predators. On the other hand numerous instances can be cited where hyaenas were observed to have done their own hunting and killing.

This does not mean of course that the Kalahari hyaena will not eat carrion under any circumstances. Indeed, they approached our camp fires almost every night, picking up bones, pieces of meat and even empty tins lying about. But the spotted hyaena inhabiting this area is primarily a hunter and scavenging seems to be the exception, and not the other way round.

Although the author has never witnessed a hyaena kill, the cases cited below are based on personal observation. With the aid of the game rangers and the Bushmen who always accompanied us it was possible in the undermentioned cases to reconstruct the whole event from the spoor prints and other signs left in the sand.

In December 1958 we found the remains of a gemsbok killed by a few hyaenas on the bare river bed of the Nossob River. There was not 
a single tree in the immediate vicinity and the hyaenas must have overpowered the gemsbok on the open ground. It was not possible to ascertain how many hyaenas took part in the kill. Some of the gemsbok's bones were carried away but from those left behind it was possible to determine that it was an adult animal, but whether it was a diseased or crippled animal is not known.

In September 1959 we found a gemsbok killed by a number of hyaenas after a long chase. When the animal was overtaken it probably decided to make a fight of it. With its back against a tree the gemsbok faced at least five hungry hyaenas and a terrific struggle must have taken place. Fighting against great odds the animal, in desperation, must have tried to make a dash for safety and about thirty yards from the spot where the struggle took place it was overpowered and killed.

In April 1960 we found eight hyaenas feeding on a freshly killed young blue wildebeest. Although the nature of the terrain made it impossible to read the footprints, there appeared to be no doubt that the hyaenas were responsible for killing the blue wildebeest.

On the same trip we saw where a gemsbok was cornered against a tree and killed by hyaenas. In the author's notes no mention was made about the number of hyaenas that took part in the killing and hence no further particulars can be supplied.

A few days later we came across the remains of a young gemsbok, about two years old, that was chased and overpowered by a lonely hyaena. What is so astonishing is that the gemsbok was almost entirely consumed by its killer and by the time that we arrived on ihe scene the hyaena was so heavily gorged that although we approached it very closely on foot it simply walked away slowly.

In June 1961 a young gemsbok was killed by a pack of four hyaenas. This happened in the open and treeless dune country, and the animal was simply run down and overpowered by its pursuers.

Numerous cases of a more or less similar nature are cited by the game wardens.

From all our observations the gemsbok appears to be the hyaena's main quarry. As the gemsbok is the most abundant of the larger antelopes in the Kalahari Gemsbok Park this is not surprising, although the gemsbok is also the hyaena's most dangerous adversary. According to the Nature Conservator blue wildebeest, eland and springbok weak in condition are also killed by hyaenas. In his own experience he has never seen a red hartebeest being killed by hyaenas. This fleetfooted antelope is probably not an easy prey for the hyaena, although old and crippled animals are bound to be killed.

As we never saw an aciual kill it was impossible to ascertain exactly how the hyaena kills its prey, but it seems to have no special technique. It simply runs its prey down and probably kills it in the same way as the African hunting dog. 
That the rather unwieldy hyaena is not more often killed by the formidable gemsbok seems io be a miracle. We once came across a dead hyaena with a wound in its belly which might have been caused by the sharp horns of a gemsbok. The Nature Conservator can recall three separate cases where a hyaena was killed by a gemsbok. In all three cases the gemsbok was chased by a pack of hyaenas and with its pursuers crowding in from all sides the pursued animal stabbed and killed one of its assailants in the run.

In spite of its lazy, cumbersome appearance the hyaena can not only travel fast, but has great staying powers. The Nature Conservator once came across the spoor of a pack of hyaenas that were pursuing a gemsbok. He followed the prints for fourteen miles before reaching the spot where the gemsbok was overtaken and killed. On another occasion a gemsbok was chased for seven miles before being killed.

One night a number of hyaenas killed a few goats near the Warden's house. The next day he followed the tracks for 25 miles before he came to their holes, from where, according to the tracks, they left the previous evening. They must, therefore, have travelled at least fifty miles in one night.

Eleven is the largest number of hyaenas found together by this author but according to the Nature Conservator packs of up to thirty hyaenas may take part in a hunt. On one occasion more than fifty hyaenas were found together at Kwang in the Nossob River. They were not found at a kill and were probably out hunting.

\section{BIBLIOGRAPHY}

Adamson, Joy, 1960: Born Free; Collins \& Harwell Press, London.

Deane, N. N., 1962: The Spooted Hyaena, Crocuta crocuta. The Lammergeier, Vol. II, No. 2.

Fitzsimons, F. W., 1925: South African Nature Study. Winderley \& Co., Cape Town.

Guggisberg, C. A. W., 1961: Simba. Howard Timmins, Cape Town.

Kearton, C., 1929: In the Land of the Lion. Arrowsmith, Bristol.

Kirby, F. V., 1899: The Great and Small Game of Africa, Bryden. (Contribution). Rowland Ward, Ltd., London.

Matthews, L. H., 1939: The bionomics of the Spotted Hyaena. Proc. Zool. Soc. London, Vol. 109, Series A.

Pitman, C. R. S., 1942: A Game Warden Takes Stock. James Nisbet \& Co., London.

Roosevelt, T. (and Heller, E), 1915: Life Histories of African Game Animals. John Murray, London.

Selous, F. C., 1908: African Nature Notes and Reminiscences. Macmillan \& Co. Ltd., London.

Slijper, E. J., 1946: Kon. Ned. Akad. Wet., Verh. (Tweede Sectie), D1, XLII, No. 5, p. 1-128.

Stevenson-Hamilton, J., 1954: Wild Life in South Africa. Cassel \& Co., London. 